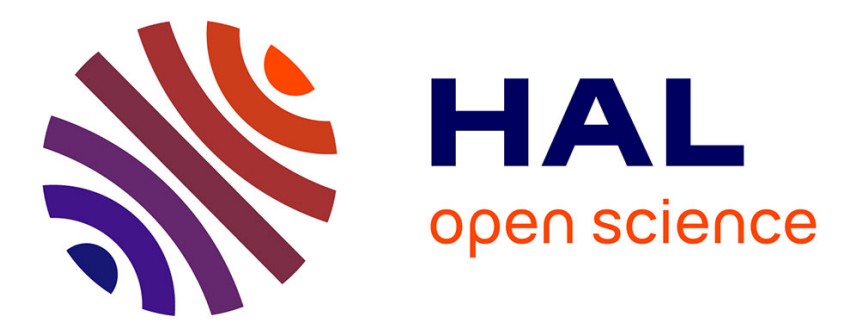

\title{
Kite Generator System: Grid Integration and Validation
} Mariam Ahmed, Ahmad Hably, Seddik Bacha, Andres Ovalle

\section{To cite this version:}

Mariam Ahmed, Ahmad Hably, Seddik Bacha, Andres Ovalle. Kite Generator System: Grid Integration and Validation. IECON 2014 - 40th Annual Conference of the IEEE Industrial Electronics Society, Oct 2014, Dallas, United States. pp.1-6. hal-01064276

\section{HAL Id: hal-01064276 https://hal.science/hal-01064276}

Submitted on 17 Sep 2014

HAL is a multi-disciplinary open access archive for the deposit and dissemination of scientific research documents, whether they are published or not. The documents may come from teaching and research institutions in France or abroad, or from public or private research centers.
L'archive ouverte pluridisciplinaire HAL, est destinée au dépôt et à la diffusion de documents scientifiques de niveau recherche, publiés ou non, émanant des établissements d'enseignement et de recherche français ou étrangers, des laboratoires publics ou privés. 


\title{
Kite Generator System: Grid Integration and Validation
}

\author{
Mariam Ahmed, Ahmad Hably ${ }^{1}$, Seddik Bacha, Andres Ovalle \\ Grenoble Electrical Engineering Laboratory (G2ELab) - 38402 Saint-Martin d'Heres, France
}

\begin{abstract}
In this paper, the problem of grid integration of a kite generator system (KGS), is handled. The mechanical power generated by the kite's traction is translated into an electrical one via a permanent magnet synchronous machine. This power is then injected in the grid or used to supply an isolated load after passing a power electronics interface. Control schemes have been developed for grid connected or stand-alone operation and tested on a hardware-in-the-loop simulator.
\end{abstract}

\section{INTRODUCTION}

In the ongoing research to decarbonize the electric grid without losing its reliability, grid integration of renewable energy resources is an important issue. During the last ten years, a high altitude wind turbines'concept has emerged and is heavily investigated by many research groups and emerging startup companies (see [2] for an overview of the international landscape). The main idea is that energy is produced from high altitudes by controlling tethered airfoils (mainly kites) to fly at high altitudes with a high crosswind speed. This develops a large pulling force that turns an onground generator, thus generating electricity. However, due to limitation in the tether's length and the power zone, the kite should always be redrawn to its initial position by using the onground machine as a motor, consuming energy as doing so.

While a lot of research is being done to optimize the kite orientation control using different control techniques such as predicitve control [6], [5], [8], observer-based control [7], virtual constraint control destined for periodic systems [3], and other control approaches [10], [4], the grid connection part is yet to be treated. The kinetic energy, captured from high altitude wind by the kite generator system (KGS), needs to be transformed into an electric power that can be injected in the electric grid or used to supply a certain load. Among the proposed power transformation systems associated to renewable energy grid integration, the one shown in Fig.1 offers a suitable solution for the relaxation-cycle nature of the studied system. The traction force of the kite is transformed

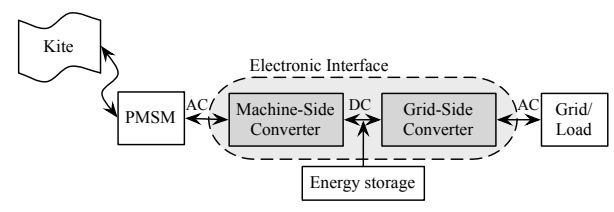

Fig. 1. Kite Generator System Block diagram.

${ }^{1}$ Corresponding author - Gipsa-lab, ahmad.hably@grenoble-inp.fr into a torque applied to an onground permanent magnet synchronous machine (PMSM). This leads to producing an alternative electrical energy with variable frequency. The machine is coupled with the grid, or with a certain load, via a power electronics interface that consists of two bidirectional AC/DC converters. An energy storage should be added in the case of a load or an isolated grid connection, in order to provide the necessary energy during the system's recovery phase. It is installed on the DC-bus level relating both converters.

The paper is organized as follows. Section II is dealing with the power transformation unit. Section III proposes the control scheme used to drive the later system for each connection mode: Infinite grid-connection and stand-alone operation. The validation results are presented in section IV where the problem of implementing the KGS on a Power Hardware-In-the-Loop (PHIL) simulator is addressed. The paper ends with conclusions.

\section{POWER Transformation System}

To insert the kite's generated mechanical power into the electrical grid, a power transformation system is needed to transform this power into an electrical one that respects to grid's codes. This system is presented and modeled in the coming paragraphs.

\section{A. Torque Transmission between the Kite and the PMSM}

The movement of the tether is transformed to a rotation by means of a drum coupled to the PMSM through a gearbox. Thus, the traction force $F_{\text {trac }}$ is translated to a torque $C_{R}$ applied on the machine. Eq.1 and Fig. 2 represent the mechanical connection:

$$
C_{G}-C_{R}-D \Omega_{S}=J \frac{d \Omega_{S}}{d t}
$$

with $\Omega_{S}=\frac{V_{L}}{K}$ is the rotation velocity, $K$ combines the gearbox factor and the drum diameter $R . J$ is the total inertia of the kite, the drum, and the machine's rotor. $C_{G}$ is the generator torque. $D$ is the damping factor estimation. Notice that the transmission chain elasticity is neglected.

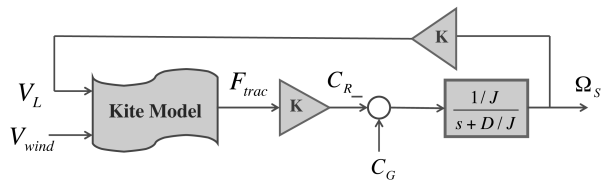

Fig. 2. Modeling of the mechanical connection between the kite and the electrical machine. 


\section{B. The PMSM's Vector Model}

Each machine's phase can be presented by the BehnEschenburg equivalent electric model of Fig.3, which consists of a resistance $R_{s}$, inductance $L_{s}$ and an electromagnetic force $e_{s k}$ for $k=\{a, b, c\}$. The model supposes the

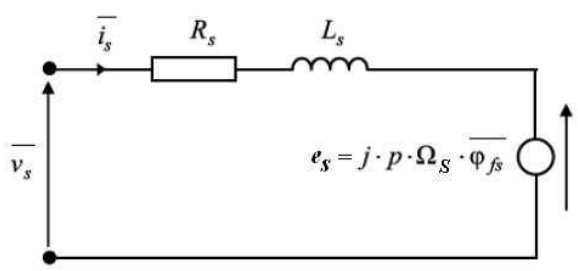

Fig. 3. PMSM's Behn-Eschenburg equivalent electrical model.

existence of a regular air gap, linear characteristics of the magnetic circuit with no saturation, and a balanced sinusoidal three-phase current behavior. To visualize the three phases at the same time, vector presentation is used, and is expressed in Park coordinates $(p, q)$ by

$$
\begin{aligned}
v_{s d} & =R_{s} i_{s d}+L_{s} \frac{d i_{s d}}{d t}-\omega L_{s} i_{s q} \\
v_{s q} & =R_{s} i_{s q}+L_{s} \frac{d i_{s q}}{d t}+\omega L_{s} i_{s d}+\omega \phi_{f s d} \\
\phi_{s d} & =L_{s} i_{s d}+\phi_{f s d} \\
\phi_{s q} & =L_{s} i_{s q} \\
C_{G} & =p \phi_{f s d} i_{s q}
\end{aligned}
$$

where

- $\bar{v}_{s}=v_{s d}+j . v_{s q}$ is the stator voltage vector.

- $\overline{i_{s}}=i_{s d}+j . i_{s q}$ is the stator current vector.

- $\phi_{f s}=\phi_{f s d}+j . \phi_{f s q}$ is the induced flow vector.

- $p$ is the number of poles pairs.

- $\omega=p \Omega_{s}$ is the electric pulsation.

\section{Power Electronics Interface}

The interface ensures frequency and voltage isolation between the PMSM and the electric grid or the connected loads, and at the same time it offers the possibility of power flow to and from the PMSM. This interface is composed of two converters AC/DC \& DC/AC (Fig.4 and Fig.5) [9] that transform the variable frequency/voltage electric power generated by the PMSM, into a standard frequency/voltage electric power that can be injected into the grid after a filtering stage. The nature of the filter depends on the connection type. The converters are controlled using vector pulse width modulation (PWM).

Both converters function as a rectifier and an inverter depending on the system's phase (generation or recovery phase), insuring a bidirectional transfer of energy.

For the machine-side converter, supposing that switches and voltage sources are perfect, and the passive elements are linear and constant, Park representation of the converter's average model is written as follows:

$$
\begin{array}{ll}
L_{s} \frac{d i_{s d}}{d t} & =\beta_{s d} \frac{U_{D C}}{2}+\omega L_{q} i_{s q}-R_{s} i_{s d} \\
L_{s} \frac{d i_{s q}}{d t} & =\beta_{s q} \frac{U_{D C}}{2}-\omega L_{d} i_{s d}-R_{s} i_{s q}-e_{s q} \\
C_{D C} \frac{d U_{D C}}{d t} & =-I_{D C}+\left(\beta_{s d} \frac{i_{s d}}{2}+\beta_{s q} \frac{i_{s q}}{2}\right)
\end{array}
$$

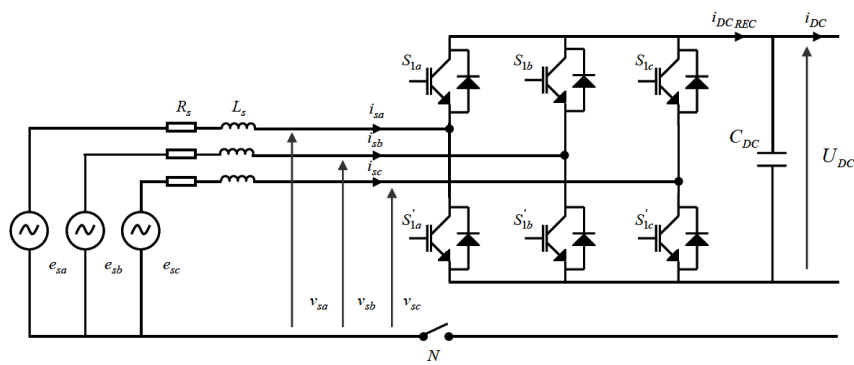

Fig. 4. Electric representation of the PMSM-side converter. PMSM is presented by Behn-Eschenburg model. $C_{d c}$ is DC-bus filtering capacitor.

where $U_{D C}$ and $I_{D C}$ are the DC bus voltage and current respectively. $\beta_{s d}$ and $\beta_{s q}$ are the average vector PWM duty cycle.

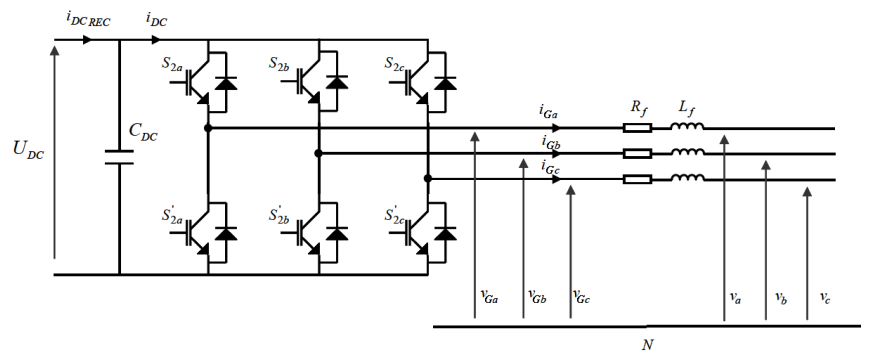

Fig. 5. Electric representation of the Grid-side converter. $R_{f}$ and $L_{f}$ represent loss and filtering components.

The same modeling approach is applied for the grid-side converter (Fig.5), which results in:

$$
\begin{aligned}
& L_{f} \frac{d i_{G d}}{d t}=-\beta_{G d} \frac{U_{D C}}{2}+\omega_{G} L_{f} i_{G q}-R_{f} i_{G d}+\sqrt{3} V_{G} \\
& L_{f} \frac{i_{G q}}{d t}=-\beta_{G q} \frac{U_{D C}}{2}+\omega_{G} L_{f} i_{G d}-R_{f} i_{G q} \\
& C_{D C} \frac{d U_{D C}}{d t}=I_{D C_{R E C}}-\left(\beta_{G d} \frac{i_{G d}}{2}+\beta_{G q} \frac{i_{G q}}{2}\right)
\end{aligned}
$$

where:

- $\omega_{G}$ is the electric grid pulsation.

- $V_{G}$ is the grid RMS voltage.

- $i_{G}^{-}=i_{G d}+i_{G q}$ is the grid currents' vector.

- $I_{D C_{R E C}}$ is the machine converter output current.

As noticed, an average model is adapted in order to have a continuous time model without switching, which allows the usage of relatively large sampling time in simulations.

\section{Control Scheme}

The control objective is to control of the tether radial velocity to generate the desired average power taking into account wind speed variations; as well as the control of electronics power interface electrical variables. Fig.6 shows the general control scheme of the power transformation system. As shown, the control scheme is divided into three levels: Low, intermediate and high. Each level functions in accordance with the system operation status: Grid-connected or stand-alone operation and are presented and discussed in the following paragraphs. 


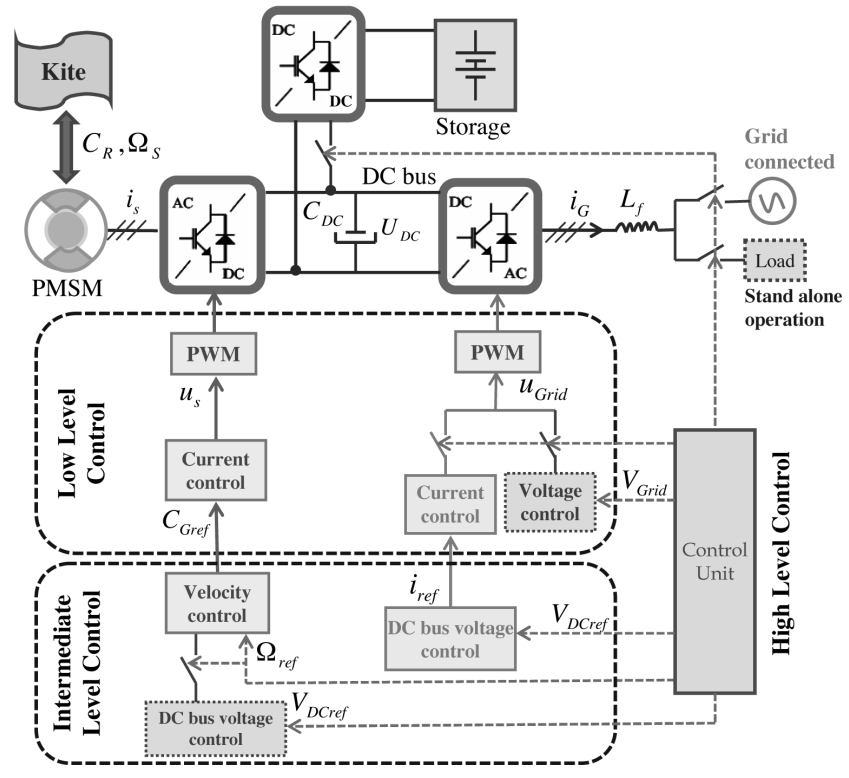

Fig. 6. General control scheme of the KGS power transformation system. Two control tracks applied depending whether the system is grid connected or in a stand-alone operation.

\section{A. Grid-connected operation}

When the KGS is connected to an infinite electric grid, the control strategy aims at extracting the maximum available energy and injecting it in the grid. Meanwhile the grid is responsible of supplying the necessary energy during the system's recovery phase. Briefly, the machine-side converter is driven to control the machine rotation velocity, and the gridside converter controls the DC-bus voltage and maintains the injected currents in phase with the grid voltages in order to preserve grid reliability.

1) Low Level Control: The low level control deals with the direct control of the converters switches. It translates higher level control laws into pulse width modulation PWM commutation rates that command the converter's switches. This conversion is done via control of the converters' output currents or voltages according to the converter operation. In the case of infinite grid connection, both are current controlled.

Considering a PMSM and taking into account that the machine and its converter are working within their nominal limits, controlling $C_{G}$ is equivalent to controlling the current $i_{s q}$ with asserting $i_{s d}=0$ (See eq.2). This allows having a maximum torque per ampere (MTPA). To control the currents, a PI controller acting in the $p-q$ rotating frame is used. The transfer function of such a controller takes the form:

$$
H_{c_{i m}}(p)=K_{p}+\frac{K_{i}}{p}=K_{p}\left(1+\frac{1}{T_{i} p}\right)
$$

with $T_{i}=K_{p} / K_{i}$, where: $K_{p}, K_{i}$ are, respectively, the corrector proportional and integral gains. These parameters are chosen in a way to have a response time much faster than that of higher control loops, as well as, a limited overshoot that does not exceed the converters maximum currents. Fig.7 shows the resulted control scheme in this case based on the converter's model given by eq.3, with: $E=p \Omega \Phi_{f s d}$. The control is done numerically in the $p-q$ space and a vector PWM is built and transmitted to the $a-b-c$ space to be injected in the switchs.

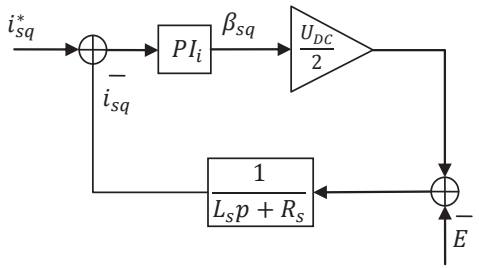

Fig. 7. Low level control scheme for the machine-side converter.

The grid-side converter's currents must be in phase with the grid voltages and have a low harmonic distortion (THD). They are controlled in the fixed coordinates a-b-c via a resonant PI controller that acts on the current harmonics desired to be eliminated. Such a controller take the following form:

$$
H_{c_{i q}}(p)=K_{p}+\sum_{n=1}^{h} \frac{2 K_{i} p}{p^{2}+\omega_{n}^{2}}
$$

where the proportional $K_{p}$ gain affects all the current harmonics equally, and the integral part $K_{i}$ affects the $h$ harmonics specified by their resonant pulse $\omega_{n}$. The gridside converter current control scheme is shown on Fig.8.

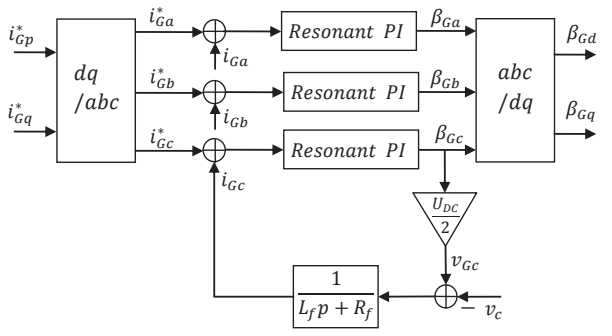

Fig. 8. Low level control scheme for the grid-side converter.

2) Intermediate Level Control: The intermediate level control loops generate the reference signals needed for the current control in the lower level via control of the PMSM rotation velocity and the DC-bus voltage. The rotation velocity is controlled by the machine-side converter using a classic PI controller similar to that of eq.5. It generates, according to the mechanical equation (eq.1), the generator torque reference, hence $i_{q}^{*}$. Considering that the current inner loop is much faster than that of the velocity, the resulted transfer function is a second order one from which the parameters of the PI corrector are determined by choosing a suitable response time that is much smaller than the KGS cycle period, and a suitable overshoot. Fig.9 shows the rotation velocity control loop, where $K_{E}=K_{G}=p \Phi_{f s d}$. The gridside converter converts the direct power to a fixed-frequency alternative power, or vice versa, according to the KGS phase 


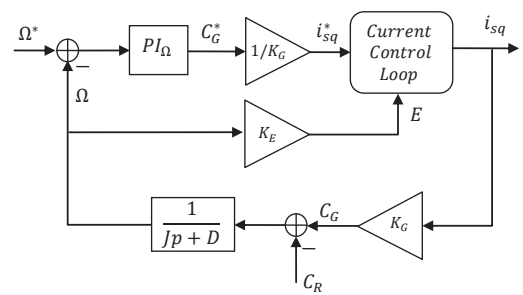

Fig. 9. Intermediate level control scheme for the machine-side converter: Machine velocity control.

(traction/recovery), hence, it is driven to control the DC-bus voltage. The DC-bus is assumed to have a resistance $R_{D C}$ and a capacitor $C_{D C}$, and once again a vector $P I$ controller is used to generate the $i_{G q}^{*}$. Fig.10 shows the resulted DC-bus voltage loop.

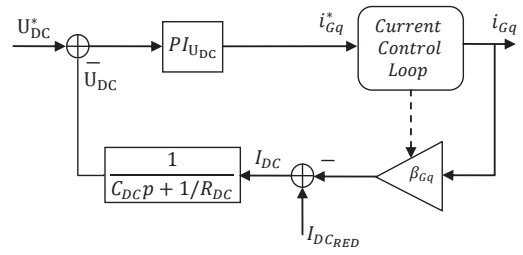

Fig. 10. Intermediate level control scheme for the grid-side converter: DC-bus voltage control.

3) High Level Control: In addition to generating the needed reference signals for the lower control levels, the high level control supervises the functioning of the system by controlling the switches that determine the power flow through it. As observed in lower control layers, the PMSM's rotational velocity control and the generator torque control are guaranteed by the PMSM-side converter. The kite applies a resistive torque $C_{R}$ that gives, when inserted in the mechanical equation, the rotation velocity $\Omega_{S}$. The velocity is corrected using a PI controller that yields a reference generator torque $C_{\text {Gref }}$. The reference rotation velocity is obtained by applying a maximum power "cycle" tracking (MPCT) algorithm that seeks the kite trajectory that guarantees a maximum average generated power.

\section{B. Stand-alone Operation}

In a stand-alone operation, the KGS cannot insure a continuous deliverance of power to the connected load or isolated grid without the support of a storage unit or additional energy sources. Instead of using a storage unit to filter the KGS output power, this can be done by supplying the load by more than one KGS whose orbits are suitably chosen in order to smooth the output power. For instance, Fig. 11 shows the output power profile resulting from using 4 kites flying in $T / 4$ delay. Different kite generator systems are connected on the DC-bus level and share the same DC/AC inverter to connect the load or the micro grid. In this case, the control goal becomes generating the needed power for the load, hence the load-connected converter's output voltages are controlled to have a constant amplitude and frequency. As a result, the machine-side converters are driven to control

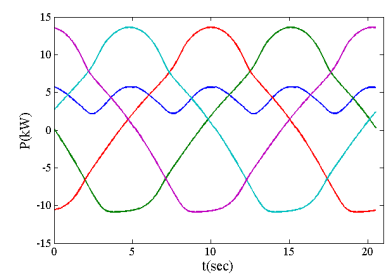

Fig. 11. Average output power of a 4-kite-based system.

the DC-bus voltage, while the grid-side converter controls the AC output voltage. On the low level of control, the machine-side converter is driven by currents as in the gridconnected operation case. Meanwhile, the grid-side converter is controlled by voltages. By adding an $L C$ filter on the output of the load-connected inverter, the converter and the load can be presented by:

$$
G(p)=\frac{1}{p^{2}+\left(\frac{1}{R C_{f}}+\frac{R_{f}}{L_{f}}\right) p+\frac{1}{L_{f} C_{f}}\left(1+\frac{R_{f}}{R}\right)}
$$

where the load is supposed to be resistive. $R$ and $R_{f}, L_{f}, C_{f}$ are the filter components.

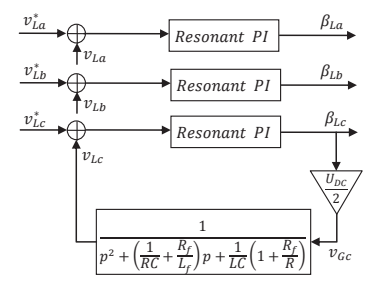

Fig. 12. Load-connected converter low level control scheme.

In the intermediate control level, as in the case of grid connection, the machine-side converter controls the machine velocity, but via the DC-bus voltage control layer. The control scheme, shown in Fig.13, results from eq.2 and using a PI corrector to regulate the DC-bus. The high level control

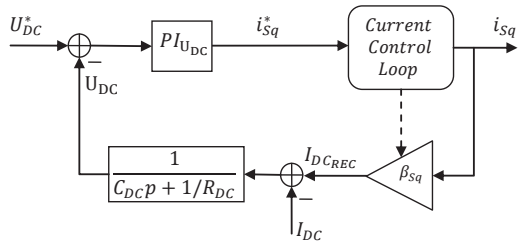

Fig. 13. Machine-connected converter Intermediate level control scheme.

determines the sinusoidal $50 \mathrm{~Hz}$-frequency voltage reference for the load voltage loop and the DC-bus reference voltage.

\section{KGS CONTROL VALIDATION}

To validate the control scheme presented previously a Power-Hardware-In-the-Loop (PHIL) of G2Elab is used. It is a real-time hybrid simulator that consists of three main parts: A direct current machine (DCM) coupled to a permanent magnets synchronous machine (PMSM), two converters (DC/AC, AC/DC), and a grid emulator. These 
hardware elements are interconnected and are supported and driven by real-time digital simulators: RT-lab and dSPACE. In this simulator, the tethered kite behavior and its associated drum and gearbox are emulated by a direct current machine (DCM), while the rest of the system is physically present. The hardware is interfaced with the real-time simulator on which the optimization and the control strategy in addition to the kite model are implemented.

Employing the PHIL-simulator instead of building a prototype is justified because the tests carried on here, focuses on the grid integration aspect, and the produced power maximization via control of the power conversion chain, and not on the kite orientation control. Furthermore, PHIL simulator requires less material and human investments, it can be modified easily to test different control strategies, and allows experimenting different test conditions in laboratory environment.

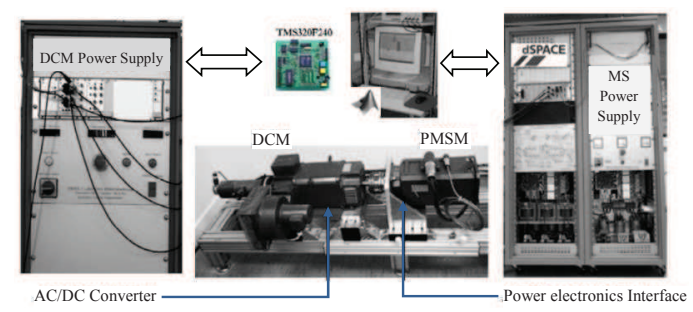

Fig. 14. PHIL Simulator

\section{A. KGS Implementation on the PHIL Simulator}

The KGS power transformation unit is physically present in the PHIL simulator while the DC-machine (DCM) replicates the behavior of the tethered kite.

1) KGS Scaling: The real-time PHIL experimental testbench in G2ELAB was not built for a single test set-up. Hence, in order to employ it to test the dynamics of the KGS, a scaling stage is needed. The testbench is characterized by a maximum power of $3 k W$ and a maximum rotation velocity of $3000 R P M$. The KGS parameters are chosen to adapt to these values. Scaling the rotation velocity and the torque can be expressed by:

$$
C_{b \max }=n C_{\max }, \quad \Omega_{b \max }=\frac{\Omega_{\max }}{m}
$$

with $n$ and $m$ being the scaling factors.

Accordingly, the power scaling equation $P_{b \max }=$ $C_{b \max } \Omega_{b \max }=\frac{n}{m} C_{\max } \Omega_{\max }=\frac{n}{m} P_{\max }$. Notice that $n \neq$ $m$ necessarily since the objective of the proposed real-time simulation is to test the dynamic behavior of the system and insure the functioning of the control strategy. However, they are chosen to be equal in order to observe the delivered power losses.

2) KGS Torque Emulation: The experimental testbench DCM is controlled to follow the dynamics of the KGS. As shown in Section.II-A, the connection between the tethered kite and the PMSM is expressed by the mechanical equation.
Replacing the kite by the DCM results in the mechanical equation (eq.9):

$$
C_{G}-C_{D C M}-D_{E} \Omega_{E}=J_{E} \frac{d \Omega_{E}}{d t}
$$

where $C_{D C M}$ is the DCM torque, $D_{E}$ is the damping factor estimation between the DCM and the PMSM and is a function of the rotation velocity $\Omega_{E}$, and $J_{E}$ is the total inertia of the DCM and the PMSM. Fig.15 represents the mechanical connection for both mentioned cases.

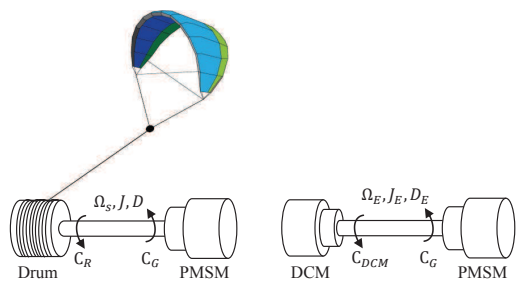

Fig. 15. Representation of the mechanical connection in the case of the KGS and the DCM.

Comparing eq. 1 and eq. 9 yields that in order to replicate the KGS behavior by the DCM, the $\Omega_{E}$ 's dynamics have to follow that of $\Omega_{s}$ and the DCM torque needs to be controlled to follow the reference in eq.10. The resulted mechanical connection is represented in Fig.16

$$
C_{D C M}^{*}=C_{R}+\left(J-J_{E}\right) \frac{d \Omega_{s}}{d t}+\left(D_{E}-D\right) \Omega_{s}
$$

Hence, the DCM torque reference consists of two parts: The tethered kite traction torque and a correction torque $C_{\text {cor }}=\left(J-J_{E}\right) \frac{d \Omega_{s}}{d t}+\left(D_{E}-D\right) \Omega_{s}$. However, computing $C_{c o r}$ is an issue in real-time applications since the rotation velocity gradient calculation induces noise, and determining the damping friction values is very difficult since they are functions of the rotation velocity [9]. In order to overcome

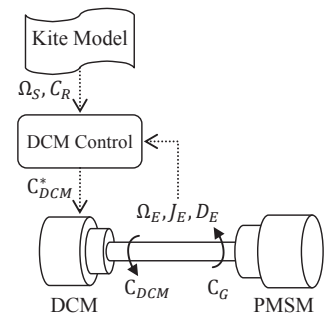

Fig. 16. KGS replication using the DCM.

these weak points, the authors in [9] modify the mentioned method by using the correction component of $C_{D C M}$ to control the DCM rotation velocity to track that of the KGS drum. Applying that to the KGS results in the control block diagram presented on Fig.17. Notice that, once velocity tracking is insured, $C_{c o r}$ becomes constant which leaves the dynamics of $C_{R}$ only. A PI controller $H_{P I}=K_{P}+\frac{K_{I}}{p}$ is used to insure tracking of the KGS rotation velocity. The open-loop transfer function of the DCM rotation velocity according to 


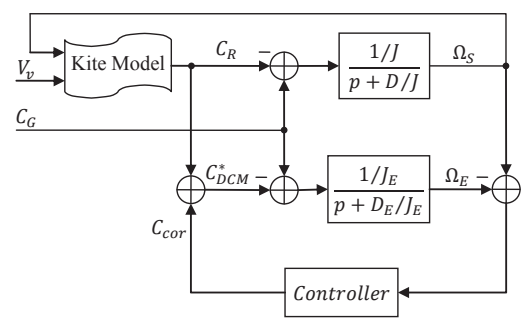

Fig. 17. KGS replication using the DCM.

the reference velocity is expressed by $\frac{\Omega_{E}(p)}{\Omega_{S}(p)}=\frac{J_{E}\left(K_{P} p+K_{I}\right)}{\left(J_{E} p+D_{E}\right) p}$. Thus the resulting closed-loop function is given in eq. 11 .

$$
H_{c l}=\frac{\tau_{P I} p+1}{\frac{p^{2}}{\omega_{n}^{2}}+\frac{2 \xi}{\omega_{n}} p+1}
$$

with $\tau_{P I}=\frac{K_{P}}{K_{I}}, \omega_{n}=\sqrt{K_{I}}$ and $\xi=\frac{1}{2 \sqrt{K_{I}}}\left(\frac{D_{E}}{J_{E}}+K_{P}\right)$. The corrector parameters are calculated according to the desired response and are dependent of the friction coefficient $D_{E}$ which is, as mentioned earlier, a function of the rotation velocity.

3) Experimental Set-up: The PHIL simulator is a hybrid semi-hardware semi-software one, in which the hardware part contains the electrical machines and the converters, while the software includes the control of those as well as the tethered kite model. The KGS testbench control scheme is shown in Fig.18. The KGS parameters, the KGS orbit optimization, the kite model as well as the MPCT algorithm are implemented on Matlab/Simulink. The Simulink model has two outputs: The traction torque and the rotation velocity reference; and two inputs: The measured velocity and power. The Simulink model communicates with RT-lab via a TCP/IP protocol functioning under Labview environment who plays the role of a server for both. The digital real-time simulator RT-lab provides an interface with dSPACE. On dSPACE, the torque emulator controller (Section.IV-A.2) generates the DCM torque reference and send it to a digital signal processor card that controls the DCM chopper. Meanwhile the control of the PMSM and the power electronics interface is performed on dSPACE. Fig.18 shows an abstract scheme of the testbench control.

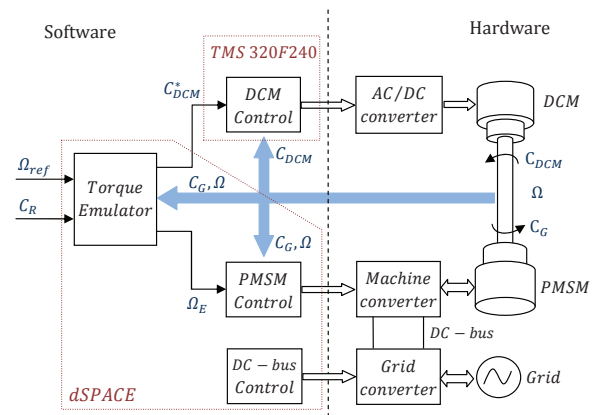

Fig. 18. KGS testbench control scheme.

\section{B. Validation}

In this section the test results of the proposed control schemes via simulation and on a PHIL simulator are presented. The KGS's parameters shown in Table.I are chosen in order to generate a radial velocity and traction torque that respect the limits imposed by the PHIL simulator [9]. After applying the optimization algorithm proposed in [1] to find the kite's optimal trajectory, hence its optimal radial velocity $V_{L}$, the next step is to transform the mechanical power produced by the PMSM into an electrical power that can be injected into the grid. This can be insured by tuning different control levels paremeters presented in the general control scheme (Fig.6). Figs.19 shows the machine phase current $I_{a S}$ and the DC bus $U_{D C}$ voltage during one period of the rotation velocity $\Omega_{S}$. It can be noticed that $U_{D C}$ is well controlled with an error less than 0.9\%. Fig.20 shows a grid phase current $I_{a-G}$ and the grid phases voltages $V_{a, b, c-G}$. The grid-side converter was successfully controlled to provide the grid with a standard $50 \mathrm{~Hz}$ three-phase voltage, and currents. The setup of Fig.14 was implemented to test

TABLE I

Kite Generator System Parameters

\begin{tabular}{|l||l||l|}
\hline$K$ & 414 & Gearbox factor $*$ rotor diameter $R(\mathrm{~m})$ \\
\hline$V$ & 4 & Wind speed $(\mathrm{m} / \mathrm{sec})$ \\
\hline$\Omega_{\max }$ & 210 & Maximum rotation velocity $(\mathrm{rd} / \mathrm{sec})$ \\
\hline$\Gamma_{\max }$ & 30 & Motor maximum torque $(\mathrm{N} . \mathrm{m})$ \\
\hline$p$ & 4 & Pole's pairs number \\
\hline$A, m$ & 5,3 & Kite's area $\left(\mathrm{m}^{2}\right)$ and mass $(\mathrm{Kg})$ \\
\hline$\rho_{a}$ & 1.2 & Air density $\left(\mathrm{kg} / \mathrm{m}^{3}\right)$ \\
\hline$C_{L}$ & 1.2 & Lift coefficient \\
\hline$C_{D}$ & 0.08 & Drag coefficient \\
\hline$r_{0}$ & 600 & Initial tether length $(\mathrm{m})$ \\
\hline
\end{tabular}

the proposed control strategy. The radial velocity control via the PMSM, the torque emulation and the electrical variables control were tested through application of the optimized radial velocity $V_{L}$ and the kite torque $C_{R}$ resulted from KGS simulations. $V_{L}$ and $C_{R}$ are scaled to match the experimental testbench characteristics. As observed on Fig.21, the resulting rotation velocity have a cyclic profile that varies in the range $[-1000,1000] \mathrm{rpm}$. Its variations are accompanied by synchronized equivalent variations in the kite torque, which

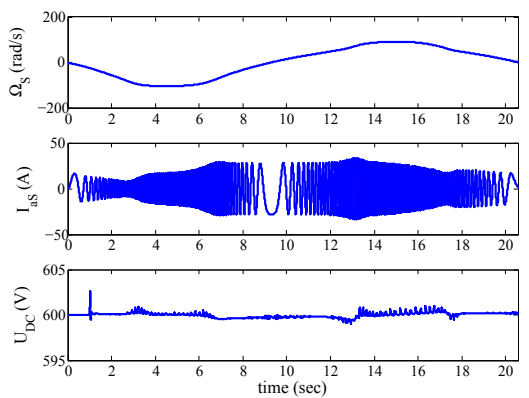

Fig. 19. Starting from the upper plot: The PMSM rotation velocity $\left(\Omega_{S}\right)$, PMSM phase current $\left(I_{a S}\right)$, DC bus voltage $\left(U_{D C}\right)$. 

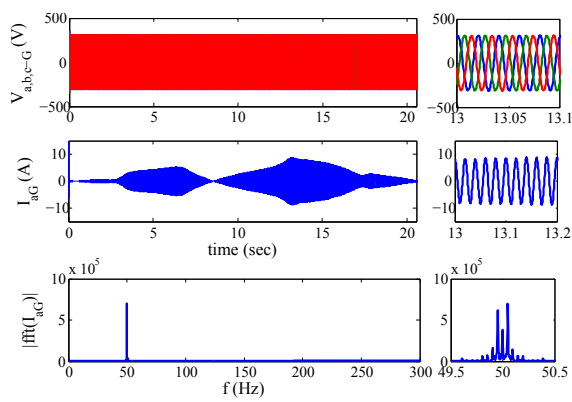

Fig. 20. Starting from above Grid voltages, grid current $\left(I_{a G}\right)$, its frequency analysis.

shows how generated power is optimized from the machine point of view. Torque and velocity variations are represented by the machine currents whose frequency, amplitude and phase change accordingly. The frequency is related directly to the rotation speed $f=\frac{\omega}{2 \pi}=\frac{p \Omega}{2 \pi}$, meanwhile the current amplitude expresses the torque variations, and the phase is inverted when the rotation velocity direction changes. Notice as well that the DC-bus voltage keeps a constant value despite the variations in the rotation velocity. For the grid-side converter electrical variables, Fig.22 shows the variations of the output current and the grid voltage following those of the rotation velocity. The current becomes zero before the rotation velocity reaches zero that is due to losses in the converters elements. This explains also why the current amplitude is higher when the velocity is negative (recovery phase) than when it is positive (generation phase).

\section{CONCLUSION}

This paper proposes a solution to KGS grid integratation. The solution is a power transformation unit consisting of a PMSM and a power electronics interface. For each connection type, a control scheme is proposed to insure the control of both the mechanical and electrical variables of the power transformation chain. The control laws are tested via simulation then validated on a Power Hardware-In-theLoop Simulator. Further work will include testing under disturbances acting on the kite and will consider the case of

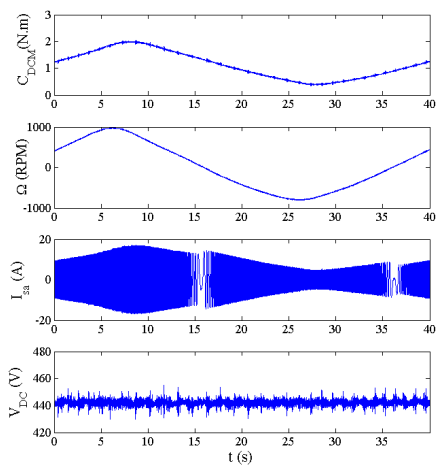

Fig. 21. Starting from above: DCM torque $\left(C_{D C M}\right)$, PMSM rotation velocity $\left(\Omega_{s}\right)$, PMSM phase current $\left(I_{s a}\right)$, and DC bus voltage $\left(U_{D C}\right)$

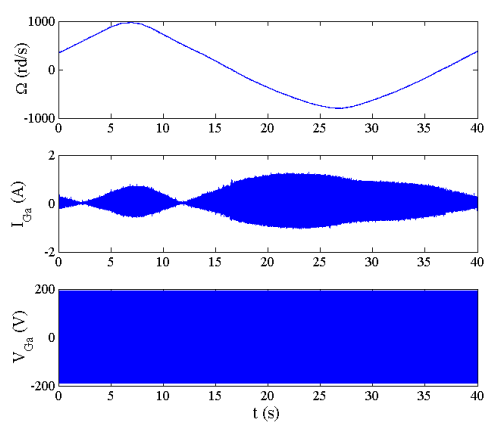

Fig. 22. Starting from the upper plot: PMSM rotation velocity $\left(\Omega_{s}\right)$, grid phase current $\left(I_{s a}\right)$, and grid phase voltage $\left(V_{G a}\right)$.

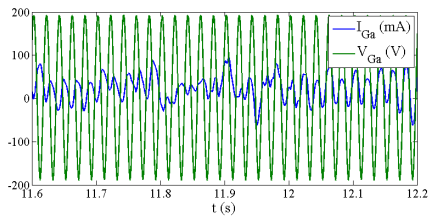

Fig. 23. Zoom into the grid voltage and current changes when the PMSM changes its rotation direction. It shows how the current is in phase with the voltage during the generation phase, and $\frac{\pi}{2}$ shifted during the recovery phase.

unbalanced regimes. They will also take into account voltage dips propagating from the grid and the system's LVRT (Low Voltage Ride Through) capabilities.

\section{REFERENCES}

[1] M.S. Ahmed, A. Hably, and S. Bacha. Power maximization of a closed-orbit kite generator system. In CDC - 50th Conference on Decision and Control Conference, Orlando, USA, pages 7717-7722. IEEE, December 2011.

[2] M.S. Ahmed, A. Hably, and S. Bacha. High altitude wind power systems: A survey on flexible power kites. In ICEM - XXth International Conference on Electrical Machines, Marseille, France, pages 2085-2091. IEEE, September 2012.

[3] M.S. Ahmed, A. Hably, and S. Bacha. Kite generator system periodic motion planning via virtual constraints. IEEE, 2013.

[4] J. H. Baayen and W.J. Ockels. Tracking control with adaption of kites. IET control theory \& applications, 6(2):182-191, 2011.

[5] M. Canale, L. Fagiano, and M. Milanese. Fast nonlinear model predictive control using set membership approximation. 17(1):1216512170, 2008

[6] M. Canale, L. Fagiano, and M. Milanese. High altitude wind energy generation using controlled power kites. IEEE Transactions On Control Systems Technology, 18(2):279-293, 2010.

[7] A. Hably, R. Lozano, M. Alamir, and J. Dumon. Observer-based control of a tethered wing wind power system : indoor real-time experiment. In ACC - American Control Conference, Washington, DC, USA, June 2013

[8] B. Houska and M. Diehl. Optimal control of towing kites. In 45th IEEE Conference on Decision and Control, pages 2693-2697, San Diego, CA, USA 2006.

[9] I. Munteanu, A.I. Bratcu, S. Bacha, D. Roye, and J. Guiraud Hardware-in-the-loop-based simulator for a class of variable-speed wind energy conversion systems: Design and performance assessment. IEEE Transactions On Energy Conversion, 25:564-576, JUNE 2010.

[10] C. Novara, L. Fagiano, and M. Milanese. Direct data-driven inverse control of a power kite for high altitude wind energy conversion. In IEEE International Conference on Control Applications (CCA), pages 240-245, 2011. 